\title{
State-Dependent Presynaptic Inhibition Regulates Central Pattern Generator Feedback to Descending Inputs
}

\author{
Dawn M. Blitz and Michael P. Nusbaum \\ Department of Neuroscience, University of Pennsylvania School of Medicine, Philadelphia, Pennsylvania 19104
}

Central pattern generators (CPGs) provide feedback to their projection neuron inputs. However, it is unknown whether this feedback is regulated and how that might shape $\mathrm{CPG}$ output. We are studying feedback from the pyloric CPG to identified projection neurons that regulate the gastric mill CPG, in the crab stomatogastric nervous system. Both CPGs are located in the stomatogastric ganglion (STG) and are influenced by projection neurons originating in the paired commissural ganglia (CoGs). Two extrinsic inputs [ventral cardiac neurons (VCNs) and postoesophageal commissure (POC) neurons] trigger distinct gastric mill rhythms despite acting via the same projection neurons [modulatory commissural neuron $1(\mathrm{MCN1})$; commissural projection neuron 2 (CPN2)]. These projection neurons receive feedback inhibition from the pyloric $\mathrm{CPG}$ interneuron anterior burster $(\mathrm{AB})$, resulting in their exhibiting pyloric-timed activity during the retraction phase of the VCN- and POC-triggered gastric mill rhythms. However, during the gastric mill protraction phase, MCN1/CPN2 exhibit pyloric-timed activity during the POC-triggered rhythm but fire tonically during the VCN-triggered rhythm. Here, we show that the latter, tonic activity pattern results from the elimination of $A B$ inhibition of $M C N 1 / C P N 2$, despite persistent $A B$ actions within the STG and $A B$ action potentials still propagating into each $C o G$. This loss of pyloric-timed $A B$ input likely results from presynaptic inhibition of $\mathrm{AB}$ in each $\mathrm{CoG}$ because, when a secondary rhythmic $\mathrm{AB}$ burst initiation zone in the $\mathrm{CoG}$ is activated, the associated action potentials are selectively suppressed during the VCN protraction phase. Thus, rhythmic CPG feedback can be locally regulated, in a state-dependent manner, enabling the same projection neurons to drive multiple motor patterns from the same neuronal circuit.

Key words: stomatogastric; presynaptic regulation; neuromodulation; rhythm; projection; crustacea

\section{Introduction}

Central pattern generator (CPG) circuits generate the motor patterns underlying rhythmic behaviors (Bellingham, 1998; Gao et al., 2001; Marder and Bucher, 2001; Kristan et al., 2005; Kiehn, 2006; Grillner et al., 2008). As a result of input from different sets of projection neurons, sensory neurons, and circulating hormones, each CPG can generate a set of distinct but related motor patterns (Rosen et al., 1991; Frost and Katz, 1996; Blitz et al., 1999; Marder and Bucher, 2007; Büschges et al., 2008; Dubuc et al., 2008; Jordan et al., 2008). CPGs can in turn provide rhythmic feedback that causes their projection neuron inputs to fire bursts that are time-locked to the CPG-generated rhythm (Gillette et al., 1978; Nusbaum, 1986; Arshavsky et al., 1988; Dubuc and Grillner, 1989; Nagy et al., 1994; Frost and Katz, 1996; Norris et al., 1996; Ezure and Tanaka, 1997; Buchanan and Einum, 2008). Thus far, however, it is unknown whether this CPG feedback is differentially regulated by distinct inputs and, if so, what its consequences might be for motor pattern generation.

We are examining local regulation of CPG feedback using the

Received June 27, 2008; revised Aug. 11, 2008; accepted Aug. 14, 2008.

This work was supported by National Institute of Neurological Disorders and Stroke Grant NS42813 (M.P.N.). We thank T. Akay and M. S. Kirby for each contributing to an experiment. We also thank W. Stein and L. Zhang for assistance with analysis scripts.

Correspondence should be addressed to Dr. Dawn M. Blitz, Department of Neuroscience, University of Pennsylvania School of Medicine, 215 Stemmler Hall, Philadelphia, PA 19104-6074. E-mail: blitzd@mail.med.upenn.edu. DOI:10.1523/JNEUROSCI.3011-08.2008

Copyright $\odot 2008$ Society for Neuroscience $\quad$ 0270-6474/08/289564-11\$15.00/0 crab stomatogastric nervous system (STNS). The STNS contains four ganglia, including the paired commissural ganglia (CoGs) and the single oesophageal (OG) and stomatogastric (STG) ganglia. The STG contains the gastric mill (chewing) and pyloric (food filtering) CPGs, whereas the CoGs and OG contain the projection neurons that regulate the STG circuits (Coleman et al., 1992; Nusbaum et al., 2001; Marder and Bucher, 2007). Similar to other rhythmic motor systems, CoG projection neurons receive feedback from the STG circuits that they regulate (Coleman and Nusbaum, 1994; Norris et al., 1994, 1996).

Several pathways, including the mechanosensory ventral cardiac neurons (VCNs) and the postoesophageal commissure (POC) neurons, trigger different gastric mill rhythms despite activating the same two projection neurons, modulatory commissural neuron 1 (MCN1) and commissural projection neuron 2 (CPN2) (Beenhakker and Nusbaum, 2004; Blitz et al., 2008). One likely contribution to these different rhythms is the distinct MCN1 and CPN2 activity patterns that occur during each rhythm (Beenhakker and Nusbaum, 2004; Blitz et al., 2008). Specifically, during the protraction phase, MCN1 and CPN2 fire tonically in the VCN-rhythm but generate pyloric rhythm-timed bursts during the POC-rhythm. In contrast, both projection neurons exhibit pyloric-timed activity during the retraction phase of both gastric mill rhythms. This pyloric-timed activity results from feedback from the pyloric pacemaker anterior burster (AB) neuron.

Here, we examined whether the apparent lack of CPG feed- 


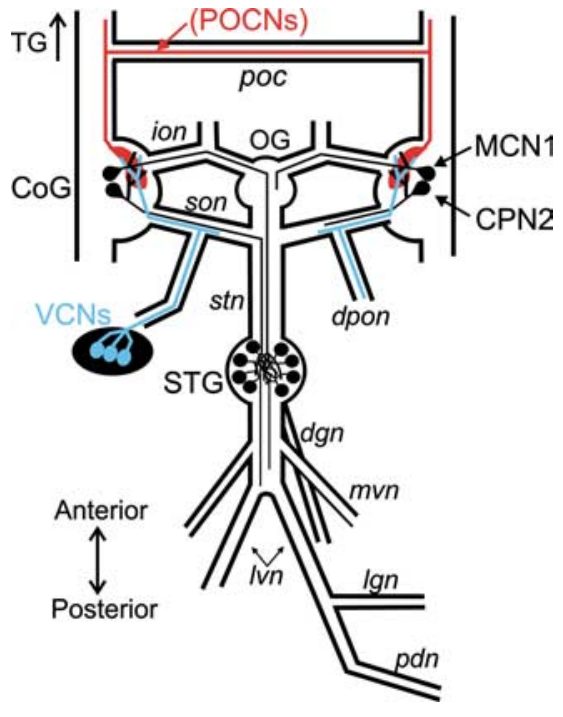

Figure 1. Schematic of the isolated stomatogastric nervous system, including identified projection neurons and extrinsic inputs. The projection neurons (MCN1, CPN2) occur as single neurons in each $\mathrm{CoG}$, from where they project through either the ion (MCN1) or son (CPN2) to innervate the STG. The extrinsic inputs (VCNs, POCNs) are bilaterally symmetric neuronal populations that innervate each CoG via either the dpon (VCNs) or the poc (POCNs). The CoG arborization of the POC neurons is depicted as a blob to reflect its dense arborization within a neurohemal organ in the anterior CoG (Goldberg et al., 1988; Messinger et al., 2005; Blitz et al., 2008). The lines projecting posteriorly from the STG represent the axons of STG motor neurons projecting toward their muscle targets. Abbreviations: ganglia: TG, thoracic ganglion; nerves: $d g n$, dorsal gastric nerve; /vn, lateral ventricular nerve; $m v n$, medial ventricular nerve; extrinsic inputs: POCNs, postoesophageal commissure neurons.

back during VCN protraction resulted from its local regulation. We found that AB-mediated inhibition in MCN1 and CPN2 was selectively eliminated during VCN protraction, despite persisting rhythmic $\mathrm{AB}$ actions within the STG and $\mathrm{AB}$ activity entering each CoG. The loss of $A B$ inhibition onto MCN1 and CPN2 during VCN protraction resulted from presynaptic inhibition of the $\mathrm{AB}$ axon terminals within each $\mathrm{CoG}$ during the VCN rhythm, but not during the POC rhythm. Thus, there is local, statedependent regulation of CPG feedback, resulting in distinct projection neuron activity patterns that contribute to the generation of different motor patterns from a single CPG circuit.

\section{Materials and Methods}

Animals. Male Cancer borealis crabs were obtained from commercial suppliers (Commercial Lobster and Seafood Company; Marine Biological Laboratory). Crabs were maintained in commercial tanks containing recirculating, filtered, and aerated artificial seawater $\left(10^{\circ} \mathrm{C}\right)$. Before dissection, crabs were cold anesthetized by packing in ice for at least $30 \mathrm{~min}$. The STNS was dissected as described previously (Blitz et al., 2004). Briefly, the foregut was removed from the animal and pinned dorsal-side down in a Sylgard 170 (K. R. Anderson; World Precision)-coated glass bowl in chilled C. borealis saline. The postoesophageal commissure (poc) (Fig. 1) was visualized with a dissecting microscope and bisected, after which the stomach was bisected ventrally and pinned flat with the interior stomach wall against the Sylgard. The STNS, including all four ganglia plus their connecting and peripheral nerves (Fig. 1), was then freed from surrounding tissue, removed from the surface of the foregut, and pinned down in a Sylgard 184 (K. R. Anderson; World Precision)-coated Petri dish. The foregut and nervous system were maintained in chilled $\left(9-12^{\circ} \mathrm{C}\right)$ saline throughout the dissection and subsequent experiment.

Solutions. C. borealis saline included the following (in mM): $440 \mathrm{NaCl}$, $26 \mathrm{MgCl}_{2}, 13 \mathrm{CaCl}_{2}, 11 \mathrm{KCl}, 10$ Trizma base, 5 maleic acid, and 5 dextrose, $\mathrm{pH}$ 7.4-7.6. High divalent cation saline (HiDi saline) consisted of the following (in mM): $440 \mathrm{NaCl}, 52 \mathrm{MgCl}_{2}, 65 \mathrm{CaCl}_{2}, 11 \mathrm{KCl}, 10$ Trizma base, 5 maleic acid, and 5 dextrose, pH 7.4-7.6. HiDi saline decreases the likelihood of activating polysynaptic pathways by raising action potential threshold, thereby also suppressing spontaneous neuronal activity (Nusbaum and Marder, 1989; Blitz and Nusbaum, 1999). When applied to the OG and CoGs, this saline decreased spontaneous activity, as was evident in extracellular recordings of the nerves [superior oesophageal nerve (son); inferior esophageal nerve (ion)] (Fig. 1) connecting these ganglia to the STG. In addition, during superfusion of HiDi saline to the anterior ganglia, spontaneous pyloric rhythm activity in the STG was weakened and resembled the activity in preparations in which the CoG output nerves were transected (Bartos and Nusbaum, 1997; Blitz and Nusbaum, 1999).

Electrophysiology. Extracellular recordings were made by isolating a small region of nerve with a petroleum jelly well (Vaseline; Medical Accessories and Supply Headquarters) and placing one of a pair of stainlesssteel wires inside the well and the other wire inside the main bath compartment. Loose-patch recordings were made by placing glass electrodes near axons in the desheathed son (Fig. 1) and applying suction to the electrode. Electrode location was altered to obtain recordings from as few axons as possible. Extracellular nerve recordings and axonal loose-patch recordings were amplified using AM Systems Model 1700 AC amplifiers and Brownlee Precision model 410 amplifiers.

Intracellular microelectrodes were made from borosilicate glass filled with $0.6 \mathrm{M} \mathrm{K}_{2} \mathrm{SO}_{4}$ plus $10 \mathrm{~mm} \mathrm{KCl}$ (current clamp, 20-25 M ; voltage clamp, 8-12 M $\Omega$ ). Intracellular signals were amplified using Axoclamp $2 \mathrm{~B}$ and 900A amplifiers (Molecular Devices) in bridge mode, discontinuous current-clamp mode (3-10 kHz sampling rate), or discontinuous single electrode voltage-clamp mode (4.5-15 kHz sampling rate), and digitized at $\sim 5 \mathrm{kHz}$ using a Micro 1401 data acquisition interface and Spike2 software (Cambridge Electronic Design). Voltage-clamp gain was $0.7-2.5 \mathrm{nA} / \mathrm{mV}$.

To facilitate intracellular recordings, ganglia were desheathed and viewed with light transmitted through a dark-field condenser (Nikon). STG and CoG neurons were identified based on their activity patterns, synaptic connectivity, and axonal projection patterns (Weimann et al., 1991; Beenhakker and Nusbaum, 2004; Saideman et al., 2007). The VCN-gastric mill rhythm was triggered by extracellular stimulation of the dorsal posterior oesophageal nerve (dpon) (Figs. 1, 2) (intraburst frequency, $15 \mathrm{~Hz}$; interburst frequency, $0.06 \mathrm{~Hz}$; burst duration, $6 \mathrm{~s}$ ) (Beenhakker and Nusbaum, 2004; Beenhakker et al., 2004). The POCgastric mill rhythm was triggered by extracellular stimulation of the poc (Figs. 1, 2) (tonic stimulation, $15 \mathrm{~Hz}$; duration, $30 \mathrm{~s}$ ) (Blitz et al., 2008). As noted above, the poc was bisected during the dissection and left and right portions were stimulated either separately or simultaneously (Blitz et al., 2008).

The pyloric rhythm was routinely monitored by an extracellular recording of the pyloric dilator nerve $(p d n)$, which contains the axons of the pyloric dilator (PD) neurons (Figs. 1, 2). PD neurons are part of the pyloric pacemaker ensemble because of their electrical coupling to the conditional oscillator AB neuron (Eisen and Marder, 1982; Miller and Selverston, 1982a,b). The gastric mill rhythm was routinely monitored via intracellular recording of the lateral gastric (LG) protractor neuron, a gastric mill CPG neuron, and/or an extracellular recording of the LG axon in the lateral gastric nerve (lgn) (Figs. 1,2).

Data analysis. Data analysis was performed using Spike2 software. Time-locked IPSPs were detected by overlapping multiple sweeps $(\geq 20$ / recording) of simultaneous recordings of $\mathrm{AB}$ and the indicated projection neuron. All recordings were aligned to the peak of $\mathrm{AB}$ action potentials. For Figure 3, we selected $A B$ action potentials from the end of each $\mathrm{AB}$ burst, to minimize the differences in the projection neuron membrane potential at the onset of each IPSP. The number of AB action potentials per pyloric-timed burst was measured from loose-patch recordings to eliminate the possibility of a change in spike number caused by impalement injury. In some figures, a raw extracellular recording (ion or son) was duplicated with the activity of a unit digitally subtracted for clarity, as indicated in each such figure legend. A custom written script in Spike2 was used to digitally subtract the secondary unit after manually inspecting the trace to verify that only that particular unit was selected for subtraction. 
Figures were made using Spike2 and CorelDraw (Corel). Statistical significance was assessed with SigmaStat (Systat Software). The paired Student $t$ test was used, and significance was considered to be $p<0.05$. Data are expressed as mean \pm SEM.

\section{Results}

The STG contains the pyloric (food filtering) and gastric mill (chewing) CPGs. The pyloric rhythm (cycle period, $\sim 0.5-2 \mathrm{~s}$ ) is a pacemaker-driven, three-phase motor pattern that is spontaneously active both in vivo and in vitro (Fig. 2, left) (Marder and Bucher, 2007). The gastric mill rhythm (cycle period, 5-20 s) is a twophase motor pattern (protraction, retraction) that is usually not spontaneously active in vivo or in vitro (Fig. 2, left) (Beenhakker et al., 2004; Marder and Bucher, 2007). Instead, its activity requires the activation of particular CoG projection neurons, such as MCN1 and CPN2 (Nusbaum et al., 2001; Beenhakker and Nusbaum, 2004; Blitz et al., 2004, 2008; Saideman et al., 2007). The gastric mill rhythm drives the alternating protraction and retraction of the paired lateral teeth and unpaired medial tooth within the gastric mill stomach compartment (Heinzel et al., 1993). In all preparations used in this study, the pyloric rhythm was spontaneously active, whereas the gastric mill rhythm was only active when triggered by VCN or POC stimulation (Fig. 2).

Stimulation of either the mechanosensory VCNs or the POC neurons triggers a lasting activation of MCN1 and CPN2, which in turn drive the gastric mill rhythm via their synaptic connections onto CPG neurons within the STG (Beenhakker and Nusbaum, 2004; Beenhakker et al., 2004; Blitz et al., 2008). However, VCN and POC stimulation trigger distinct gastric mill rhythms along with rhythm-specific activity patterns in MCN1 and CPN2. For example, MCN1 and CPN2 exhibit pyloric-timed activity during both phases of the POC-gastric mill rhythm, whereas their activity is also pyloric timed during VCN retraction but is tonic during VCN protraction (Fig. 2, right) (Beenhakker and Nusbaum, 2004; Beenhakker et al., 2004; Blitz et al., 2008). Insofar as these two projection neurons drive the activity of the protractor neuron LG (Coleman and Nusbaum, 1994; Norris et al., 1994), LG also generates pyloric-timed bursts during the POC rhythm and tonic bursts during the VCN rhythm (Fig. 2) (Beenhakker and Nusbaum, 2004; Beenhakker et al., 2004; Blitz et al., 2008).

\section{MCN1 and CPN2 receive feedback inhibition from a pyloric CPG neuron}

All four identified CoG projection neurons, including MCN1, $\mathrm{CPN} 2$, and modulatory commissural neurons 5 and 7 (MCN5, MCN7), exhibit pyloric-timed activity caused by feedback from the pyloric CPG (Coleman and Nusbaum, 1994; Norris et al., 1994, 1996; Beenhakker and Nusbaum, 2004; Beenhakker et al., 2004). The pyloric pacemaker neuron $A B$ is the likely source of the pyloric-timed activity in the projection neurons, because the $\mathrm{AB}$ neuron is the only pyloric neuron that projects to the CoGs
(Fig. 3A) (Claiborne and Ayers, 1987). In turn, several of these projection neurons, including $\mathrm{MCN} 1$, excite the $\mathrm{AB}$ neuron (Norris et al., 1996; Bartos and Nusbaum, 1997).

Each of the four identified $\mathrm{CoG}$ projection neuron receives IPSPs that occur during the $\mathrm{AB} / \mathrm{PD}$ neuron phase of the pyloric rhythm (Fig. 3B) (Coleman and Nusbaum, 1994; Norris et al., 1994, 1996; Beenhakker and Nusbaum, 2004; Beenhakker et al., 2004). We confirmed this synaptic relationship by pairing extracellular recordings of the $\mathrm{AB}$ axon in the stomatogastric nerve (stn) (Fig. 1) with intracellular recordings of the identified CoG projection neurons. For example, the overlay of multiple sweeps aligned to the peak of the $\mathrm{AB}$ action potential in Figure $3 C$ illustrates the consistent presence of a discrete IPSP in these projection neurons after every $\mathrm{AB}$ action potential $(\mathrm{MCN} 1, n=8$; CPN2, $n=3$; MCN5, $n=5$ ).

The reliability of these AB-elicited IPSPs in the identified projection neurons suggested that there was a direct synapse from $A B$ to each of them. To further assess whether these were direct connections, we superfused the anterior region of the STNS, including the desheathed OG and CoGs, with HiDi saline to increase action potential threshold and decrease the likelihood of $\mathrm{AB}$ activating an intervening neuron (see Materials and Methods). In the presence of HiDi saline, rhythmic $\mathrm{AB} / \mathrm{PD}$-timed inhibition of the $\mathrm{CoG}$ projection neurons persisted (MCN1, $n=2$ of 2 ; MCN5, $n=2$ of 2), supporting the likelihood that the $\mathrm{AB}$ neuron directly inhibited these projection neurons. 


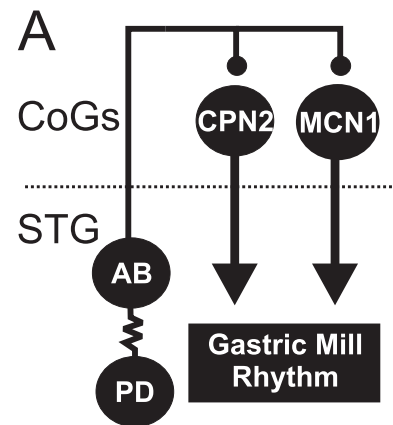

B

(PD)

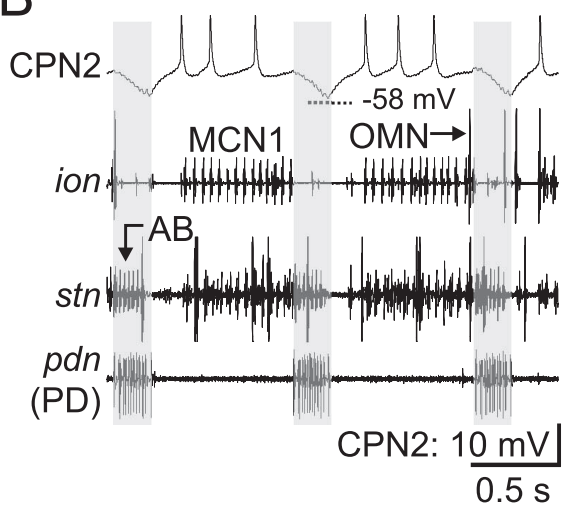

C
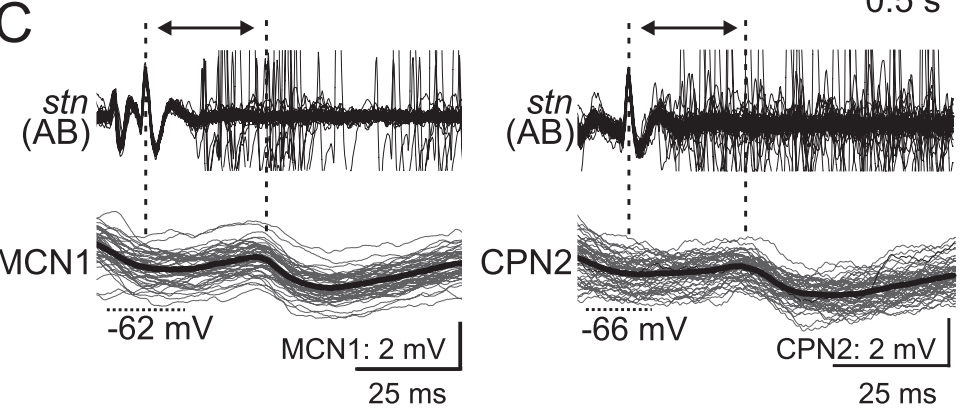

Figure 3. The pyloric pacemaker neuron, $A B$, inhibits $M C N 1$ and $C P N 2$ in the $C 0 G s$. $A$, Schematic diagram indicating that the $A B$ interneuron projects from the STG to the CoGs, where it inhibits MCN1 and CPN2. Note that AB and the PD motor neurons are electrically coupled, enabling them to fire in phase (Eisen and Marder, 1982; Miller and Selverston, 1982a,b). The PD neurons do not project to the CoGs. Filled circles, Synaptic inhibition; resistor, nonrectifying electrical coupling; arrows, projection path. $\boldsymbol{B}$, The activity of the projection neurons (PN2 and MCN1 was inhibited during each AB/PD burst (gray bars). C, Reliably occurring IPSPs were recorded in MCN1 and CPN2 after each AB action potential (recorded extracellularly in the stn). Each collection of IPSPs in MCN1 and CPN2 represents 50 sweeps triggered by an AB action potential. The thick black lines are the average of each set of 50 sweeps. The vertical dashed lines indicate the latency from the peak of the $A B$ action potential to the onset of the IPSPS. The AB recording site in the stn was $\sim 1.5 \mathrm{~cm}$ from the $\mathrm{C} 0 \mathrm{G}$. The observed latencies are consistent with those reported for $\mathrm{CoG}$ projection neuron-initiated action potentials in comparably sized axons traveling this distance to the STG and eliciting PSPs in target neurons (Coleman et al., 1995; Norris et al., 1996). The recordings in $\boldsymbol{B}$ and the left and right recordings in $\boldsymbol{C}$ are from three different preparations.

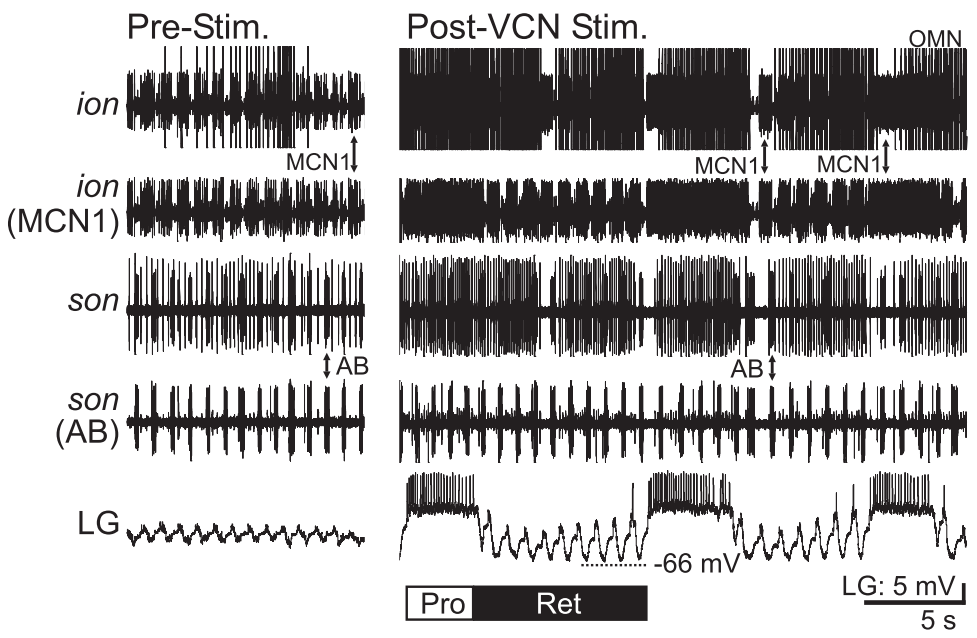

Figure 4. The activity of the $A B$ neuron proximal to the $C 0 G$ s is not inhibited during the protraction phase of the VCN-triggered gastric mill rhythm. Left, Before VCN stimulation, there was no gastric mill rhythm (LG silent), but there was an ongoing pyloric rhythm ( $A B)$. Note that the $A B$ recording was from a loose-patch recording of its axon in the son nerve (Fig. 1). Right, After VCN stimulation triggered the gastric mill rhythm, $A B$ fired rhythmic bursts of action potentials throughout both retraction (Ret) and protraction (Pro), despite the tonic MCN1 activity during protraction. The bottom ion recording is a duplicate of the top ion recording except that the oesophageal motor neuron (OMN) was digitally subtracted to better illustrate the MCN1 activity pattern. Likewise, the bottom son recording is a duplicate of the top son recording with an additional, larger amplitude oesophageal-timed unit digitally subtracted for clarity (see Materials and Methods).
$A B$ neuron activity persists proximal to the CoGs during VCN protraction The loss of pyloric-timed activity in MCN1 and CPN2 during VCN protraction might have resulted from suppression of the pyloric rhythm during this phase of the gastric mill rhythm. However, this was not the case because the pyloric rhythm consistently persisted throughout both phases of the VCNtriggered gastric mill rhythm (Fig. $2 B$ ) ( $n=29$ of 29 preparations).

Given that MCN1 and CPN2 are inhibited by $\mathrm{AB}$ but fire tonically during $\mathrm{VCN}$ protraction despite an ongoing pyloric rhythm, it is possible that the $\mathrm{AB}$ action potentials were phasically suppressed at or near the STG during the protraction phase of the VCN-gastric mill rhythm. This was a possibility because, within the STG, AB synaptic transmission is mediated primarily by graded transmitter release (Raper, 1979; Graubard et al., 1980, 1983; Anderson and Barker, 1981). Thus, suppression of $\mathrm{AB}$ action potentials could occur without having much impact on the ability of $\mathrm{AB}$ to drive the pyloric rhythm in the STG. However, by recording $\mathrm{AB}$ activity extracellularly near the entrance to the CoG, we found that $\mathrm{AB}$ action potentials were not eliminated proximal to the $\mathrm{CoG}$ during VCN protraction (Fig. 4). Specifically, rhythmic $\mathrm{AB}$ neuron activity persisted at the level of the son nerves after the VCNgastric mill rhythm was triggered, during both protraction and retraction (Fig. 4) $(n=6$ of 6$)$. Furthermore, there was no difference in the number of $A B$ action potentials nor its firing frequency during the retractor and protractor phases of the VCN-gastric mill rhythm (AB spike number: protraction, $6.0 \pm 0.2$; retraction, $5.8 \pm 0.1, p>0.05, n=4$; firing frequency: protraction, $28.0 \pm 1.8 \mathrm{~Hz}$; retraction, $29.6 \pm 1.1, p>0.05, n=4)$. This result suggested the possibility that the $\mathrm{AB}$ neuron activity was locally regulated within each CoG.

\section{Local regulation of $A B$ synapses onto} CoG projection neurons

As an initial approach to determine the site at which the $A B$ neuron synaptic actions onto $\mathrm{CoG}$ projection neurons was being regulated during VCN protraction, we took advantage of the bilaterally symmetric nature of the anterior STNS and stimulated the VCN and POC pathways on opposite sides (Fig. 5). The gastric mill rhythm that was triggered by this costimulation commonly included a mixture of VCN-like (tonic) and POC-like (pylorictimed) LG neuron activity (Fig. 5). How- 


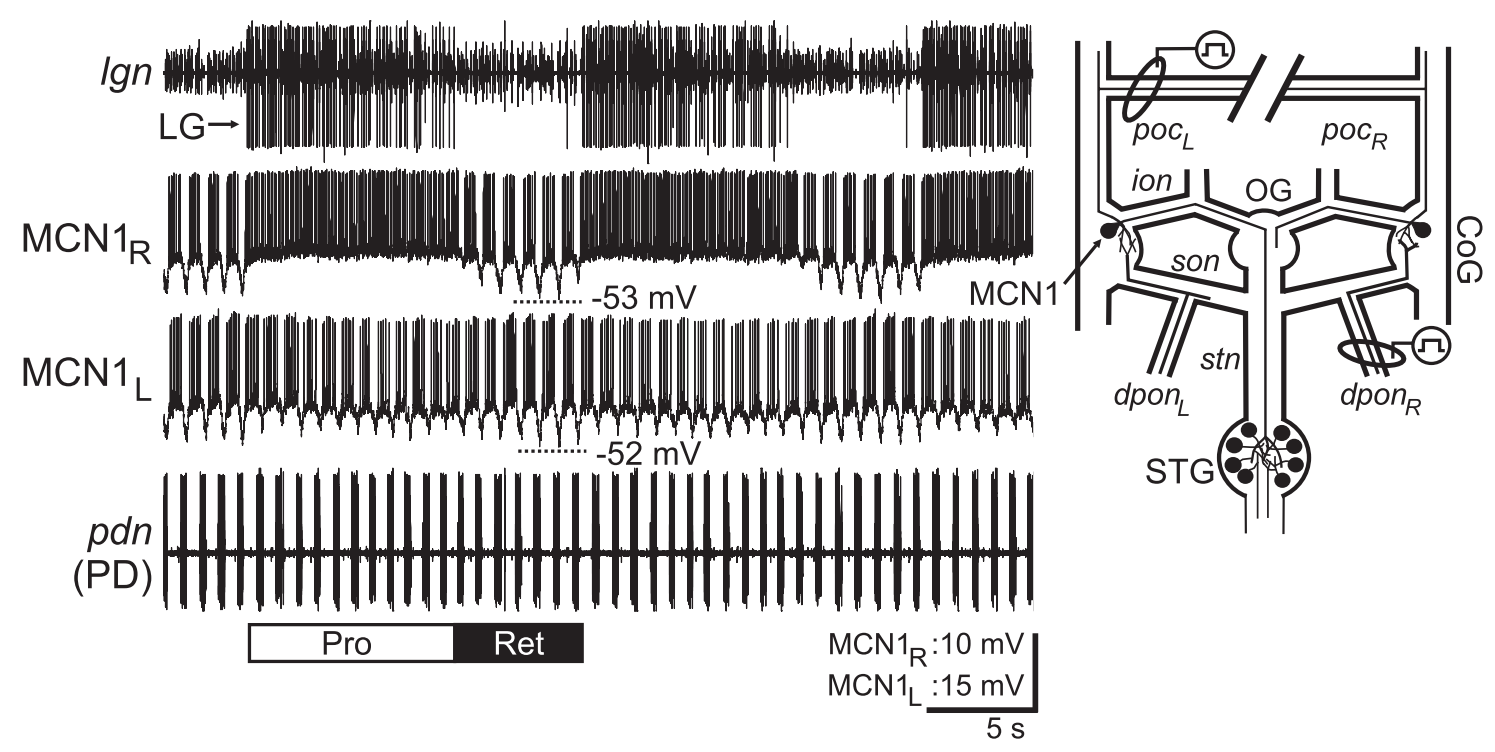

Figure 5. The synaptic actions of the $A B$ neuron are separately regulated in each COG. Costimulation of $V C N s_{\text {Right }}$ and $P O C S_{\text {Left }}$ triggered a gastric mill rhythm $(L G)$ during which $M C N 1_{R}$ and $M C N 1_{L}$ exhibited distinct protraction-phase activity patterns. Left, The AB-mediated inhibition was apparent in both MCN1s during each retractor phase (Ret) because their activity was interrupted during each $A B / P D$ burst $(p d n)$. In contrast, during protraction (Pro) the $M C N 1_{R}$ (VCN-stimulated side) fired tonically, whereas $M C N 1_{L}$ (POC-stimulated side) continued to exhibit a pyloric-timed activity pattern. Right, Schematic illustration of the sites of stimulation for the POCNs $\left(p o C_{L}\right)$ and VCNs $\left(d p o n_{R}\right)$. Note that the diagonal bars through the poc indicate that this commissure was transected before nerve stimulation (Blitz et al., 2008).

ever, the associated protraction phase activity pattern of each MCN1 reflected the pattern expected to occur based on the pathway used to activate it. Specifically, the MCN1 protraction phase activity pattern was tonic on the VCN-stimulated side, whereas it was pyloric-timed on the POC-stimulated side $(n=5)$ (Fig. 5$)$. This result further supported the hypothesis that the tonic firing in MCN1 and CPN2 during VCN protraction was not attributable to a global change in $\mathrm{AB}$ activity but occurred locally within each CoG. It further suggested that the decreased efficacy of $A B$ inhibition onto MCN1 and CPN2 occurred via a postsynaptic shunting of the $\mathrm{AB}$ inhibition in the projection neurons and/or a presynaptic inhibition of the $\mathrm{AB}$ axon terminals in the CoGs $\left(\mathrm{AB}_{\mathrm{CoG}}\right)$.

The possibility that the decreased efficacy of $A B$ inhibition in the CoG resulted from a postsynaptic shunting mechanism seemed unlikely because the same event would have to occur with a consistent effectiveness in all four identified CoG projection neurons (MCN1, CPN2, MCN5, MCN7). This is because these four projection neurons all lose their pyloric-timed inhibitory input during VCN protraction (Norris et al., 1994, 1996; Beenhakker et al., 2004). This occurs in MCN5 ( $n=8$ of 8 ) and MCN7 ( $n=1$ of 1 ) despite the fact that they do not contribute to driving the VCN-gastric mill rhythm and are either inactive or weakly active after VCN stimulation (Beenhakker and Nusbaum, 2004; Beenhakker et al., 2004). These observations suggested that a single event that would have a simultaneous and equivalent impact on all four projection neurons, such as presynaptic inhibition of $\mathrm{AB}_{\mathrm{CoG}}$, was more likely to mediate the loss of pylorictimed activity during VCN protraction in these neurons.

\section{Presynaptic inhibition of the $\mathrm{AB}$ axon terminals in each CoG} To determine whether the $\mathrm{AB}$ inhibition of CoG projection neurons was being suppressed presynaptically or postsynaptically, we recorded $\mathrm{AB}$-mediated IPSCs with voltage-clamp recordings of MCN1 and CPN2. During these recordings, pyloric rhythmtimed barrages of AB-mediated IPSCs were consistently recorded in MCN1 $(n=12)$ and $\mathrm{CPN} 2(n=12)$ (Fig. $6 A)$. After VCN stimulation, the AB-mediated IPSCs were selectively eliminated in both MCN1 $(n=8$ of 8$)$ and CPN2 $(n=8$ of 8$)$ during VCN protraction (Fig. $6 \mathrm{~B}$ ). When the VCN-gastric mill rhythm eventually terminated, these IPSCs again occurred during every cycle of the pyloric rhythm (MCN1, $n=6$ of 6 ; CPN2, $n=6$ of 6 ). During these experiments, we stimulated the left and right VCN (or POC, see below) pathways so that the contralateral MCN1 or CPN2 activity would continue to drive the gastric mill rhythm when we placed MCN1 or CPN2 into voltage clamp and eliminated its activity. During protraction, the current level in both MCN1 ( $n=7$ of 8$)$ and CPN2 $(n=8$ of 8$)$ was consistently more negative than the current measured during the trough in between the bouts of AB IPSCs. We did not pursue the underlying cause of this distinction.

Consistent with the hypothesis that there was a single event underlying the loss of pyloric-timed activity during VCN protraction in all four identified CoG projection neurons, the $\mathrm{AB}$ mediated IPSCs were also eliminated in MCN5 $(n=8$ of 8$)$ and MCN7 ( $n=1$ of 1 ) during VCN protraction. This result further implicated the single event as being a presynaptic inhibition of $\mathrm{AB}_{\mathrm{CoG}}$ and not a postsynaptic shunting of the influence of the $\mathrm{AB}$ synapse.

The elimination of AB-mediated IPSCs in MCN1 and CPN2 was specific to the VCN-type of gastric mill rhythm. During POC-gastric mill rhythms, the rhythmic barrages of $\mathrm{AB}$ mediated IPSCs occurred during both protraction and retraction phases in MCN1 ( $n=4$ of 4$)$ and CPN2 ( $n=4$ of 4 ) (Fig. 7 ).

To assess further whether there was presynaptic inhibition of $\mathrm{AB}_{\mathrm{CoG}}$, we took advantage of the presence of a secondary burst initiation zone in $\mathrm{AB}_{\mathrm{CoG}}$. Multiple spike or burst initiation zones are found in many neurons, with a primary/dominant zone defined as the one with the fastest intrinsic firing rate (Calabrese and Kennedy, 1974; Moulins et al., 1979; Meyrand et al., 1992; Zecević, 1996; Bucher et al., 2003). In such cases, when the primary zone is hyperpolarized, other zones can become active (Calabrese, 1980). In rhythmically bursting neurons, the secondary zone can generate bursts of action potentials (Calabrese, 1980). 


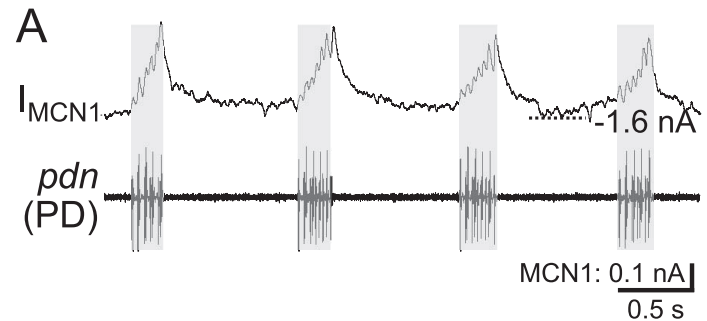

B Post-VCN Stim.

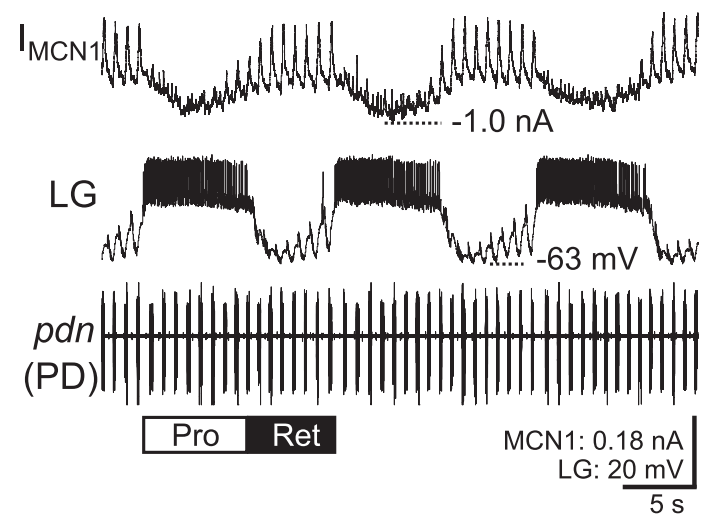

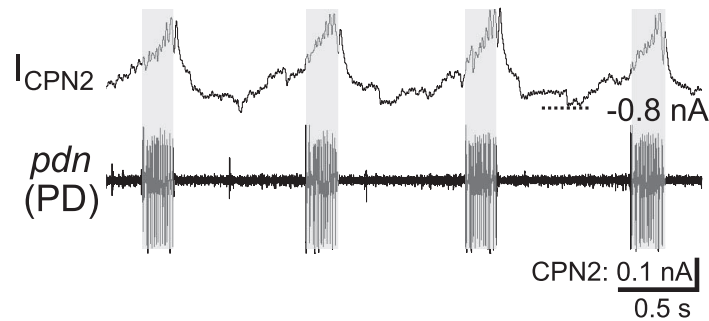

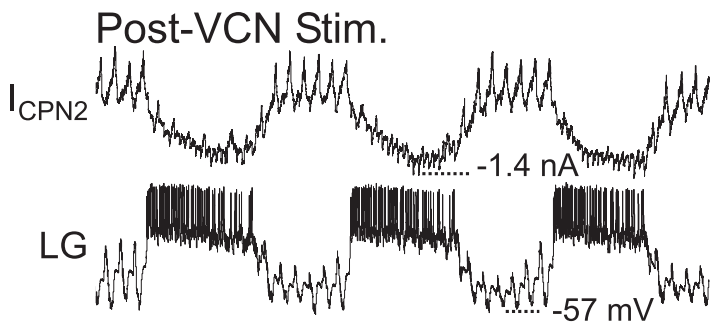

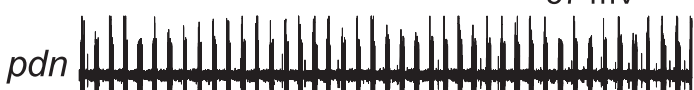
(PD)

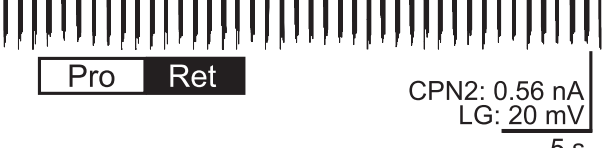

Figure 6. The AB neuron-mediated IPSCS in MCN1 and CPN2 are eliminated during the protraction phase of the VCN-triggered gastric mill rhythm. $A$, During an ongoing pyloric rhythm (PD), pyloric rhythm-timed barrages of AB-mediated IPSCs (gray bars) occurred in MCN1 (left) and CPN2 (right). The left and right panels are from different preparations. The holding potential was - 60 $\mathrm{mV}$ for MCN1 and $-65 \mathrm{mV}$ for CPN2. B, During the VCN-triggered gastric mill rhythm (indicated by the tonic LG bursts), the AB-mediated IPSCs in both MCN1 (left) and CPN2 (right) were present during each retractor phase (Ret). However, these IPSCs were eliminated during each protractor phase (Pro), despite the continued presence of the pyloric rhythm in the STG (PD). The left and right panels are from different preparations. The holding potential was $-65 \mathrm{mV}$ for MCN1 and $-70 \mathrm{mV}$ for CPN2.

After VCN stimulation, hyperpolarizing the STG region of the $\mathrm{AB}$ neuron $\left(\mathrm{AB}_{\mathrm{STG}}\right)$ consistently activated a secondary $\mathrm{AB}$ burst initiation zone in the CoGs $(n=7)$. We hyperpolarized $\mathrm{AB}_{\mathrm{STG}}$ either directly or indirectly via the electrically coupled PD and/or LPG (lateral posterior gastric) neurons. The activation of a secondary $\mathrm{AB}$ burst initiation zone was evident by recording the $\mathrm{AB}$ neuron at multiple sites simultaneously, including an intraaxonal $\mathrm{AB}$ recording near the STG and extracellular stn and/or son recordings located more anteriorly (Fig. $8 A$ ). In some experiments, we instead obtained a loose-patch $\mathrm{AB}$ axon recording in the son (Fig. $8 \mathrm{~A}$ ). In the absence of hyperpolarizing current injection, the $\mathrm{AB}$ action potentials always initiated near the STG and occurred later in the $\operatorname{stn}$ and $\operatorname{son}(n=10$ of 10$)$ (Fig. $8 B$ ). In contrast, when $\mathrm{AB}_{\mathrm{STG}}$ was hyperpolarized, the $\mathrm{AB}$ action potentials occurred first in the son and propagated toward the STG $(n=4$ of 4$)$ (Fig. $8 B$ ). These antidromic AB action potentials occurred in rhythmic bursts with a longer cycle period than the orthodromic $\mathrm{AB}$ bursts (Fig. $8 \mathrm{C}$ ). The CoG burst initiation zone consistently elicited rhythmic bursts with longer cycle periods than the STG burst initiation zone (control, $1.14 \pm 0.1 \mathrm{~s} ; \mathrm{AB}_{\mathrm{STG}}$ hyperpolarized, $1.73 \pm 0.2 \mathrm{~s} ; p<0.05 ; n=6)$. Although consistently longer than the control pyloric cycle periods, the $\mathrm{AB}$ antidromic burst cycle periods were similar to typical pyloric cycle periods (0.5-2 s), and distinct from gastric mill cycle periods (5-20 s) (Beenhakker et al., 2004; Marder and Bucher, 2007).

At the STG, the antidromic bursts of $\mathrm{AB}$ action potentials propagated into the region in which the $A B$ membrane potential was held hyperpolarized by current injection, which prevented transmitter release from $\mathrm{AB}_{\mathrm{STG}}$. Consequently, at these times no pyloric rhythm occurred ( $n=6$ of 6 ) (Fig. $8 C$ ). These AB action potentials were, however, effective in the CoGs as is evident from the associated disruptions in MCN1 activity $(n=6 \mathrm{MCN} 1 \mathrm{~s}$ in five preparations) (Fig. 8C).

We used these CoG-initiated $\mathrm{AB}$ action potential bursts, recorded intra-axonally in $\mathrm{AB}$ near the STG, to assess the possibility that $\mathrm{AB}$ was presynaptically inhibited during $\mathrm{VCN}$ protraction. We anticipated that, if $\mathrm{AB}$ was indeed presynaptically inhibited, then the antidromic $\mathrm{AB}$ bursts would likely be selectively eliminated during $\mathrm{VCN}$ protraction. In each experiment, before hyperpolarizing $\mathrm{AB}_{\mathrm{STG}}$ to activate its CoG burst initiation zone, $\mathrm{AB}$ exhibited pyloric-timed membrane potential oscillations with action potential bursts at the depolarized peak of each oscillation (Fig. 9A). These AB bursts were coactive with the PD neurons, as occurs consistently during the pyloric rhythm (Marder and Bucher, 2007). We then triggered the VCN-gastric mill rhythm and found that the pyloric-timed $\mathrm{AB}_{\mathrm{STG}}$ activity persisted, as usual, during both protraction and retraction (Fig. 9B). In contrast, when $\mathrm{AB}_{\mathrm{STG}}$ was hyperpolarized and its CoG burst initiation zone was activated, the CoG-initiated $\mathrm{AB}$ action potentials persisted during VCN retraction but were consistently eliminated during each protraction phase $(n=6$ of 6 ) (Fig. 9C). This result supported the occurrence of presynaptic inhibition of $\mathrm{AB}_{\mathrm{CoG}}$ during $\mathrm{VCN}$ protraction.

\section{Discussion}

In this study, we determined that CPG feedback to its descending inputs is locally regulated, in a state-dependent manner. Specifically, after stimulating the mechanosensory VCN pathway, there was a gastric mill rhythm-timed presynaptic inhibition of the $\mathrm{AB}_{\mathrm{CoG}}$ axon terminals. This presynaptic inhibition occurred during each gastric mill protractor phase, eliminating the inhibitory synaptic actions of $\mathrm{AB}$ on the $\mathrm{CoG}$ projection neurons, including 
MCN1 and CPN2, and changing their activity pattern from pyloric-timed to tonic. We found no evidence for comparable events during the POC-gastric mill rhythm (Fig. 10). The distinct activity patterns in MCN1 and CPN2 during these two gastric mill rhythms contributed to their ability to drive different versions of the gastric mill rhythm (Beenhakker and Nusbaum, 2004; Blitz et al., 2008) (Fig. 10). The presence of CPG feedback to its descending inputs is well documented in motor systems, as is its ability to impose a rhythmic activity pattern on these inputs (Gillette et al., 1978; Nusbaum, 1986; Arshavsky et al., 1988; Dubuc and Grillner, 1989; Nagy et al., 1994; Frost and Katz, 1996; Norris et al., 1996; Ezure and Tanaka, 1997; Buchanan and Einum, 2008). To our knowledge, the ability of such CPG feedback to be locally regulated at the site of its feedback synapses has not been previously demonstrated.

Local regulation of $\mathrm{AB}$ neuron activity in the CoGs enables it to continue to function in other regions of the nervous system. For example, it continues to drive the pyloric rhythm in the STG during times when its transmitter release is suppressed in the CoGs. Comparable presynaptic regulation of transmitter release is a common feature of all nervous systems (Chevaleyre et al., 2006; Rossignol et al., 2006; Pelkey and McBain, 2007; El Manira et al., 2008; Pinheiro and Mulle, 2008). More specifically with respect to motor systems, presynaptic regulation of transmitter release not only influences CPG feedback to projection neurons as shown here for the $\mathrm{AB}$ feedback pathway, but it also focally regulates feedforward input onto CPGs (Coleman and Nusbaum, 1994; Lomelí et al., 1998; Perrins and Weiss, 1998; Westberg et al., 2000; Sasaki et al., 2007).

Aside from changing the activity pattern of its projection neuron targets, the function of the CPG feedback pathway remains to be determined in most systems. In the isolated STNS, one documented function for CPG feedback to projection neurons is to enable the pyloric circuit to regulate the gastric mill rhythm (Wood et al., 2004). For example, when MCN1 activity is pylorictimed, the gastric mill protractor LG neuron also exhibits pylorictimed bursts, as occurs during the POC-gastric mill rhythm. When MCN1 activity is tonic, the LG bursts are tonic, as occurs during the VCN-gastric mill rhythm. These distinct protractor phase activity patterns appear to have behavioral correlates insofar as, in intact crabs, the lateral teeth can protract either smoothly or in a pyloric-timed manner (Heinzel et al., 1993). Although the behavioral function of these two chewing modes is not known, their presence supports the need for the motor system to generate these distinct motor patterns.

The gastric mill-timed presynaptic inhibition of $\mathrm{AB}$ also provides a timing cue to $\mathrm{CoG}$ neurons regarding the ongoing gastric mill rhythm. Thus, during the VCN-gastric mill rhythm, the CoG neurons that are targets of $\mathrm{AB}$ exhibit activity patterns timed to both the pyloric and gastric mill rhythms. This information may be used to coordinate the gastric mill and pyloric rhythms with other motor systems. Coordination between different rhythmic behaviors is common in all animals, such as the coordination between locomotion and respiration (Bramble and Carrier, 1983; Kawahara et al., 1989; Syed and Winlow, 1991; Morin and Viala, 2002; Saunders et al., 2004). Such intercircuit coordination exhibits flexibility, including changes in coupling ratios as well as a complete loss of coordination under different behavioral conditions (Bernasconi and Kohl, 1993; Clemens et al., 1998; Saunders et al., 2004). Although little is known regarding the underlying cellular mechanisms, state-dependent local regulation of CPG feedback seems well suited to play a role in these events. In other systems, there are also neurons in higher centers that exhibit
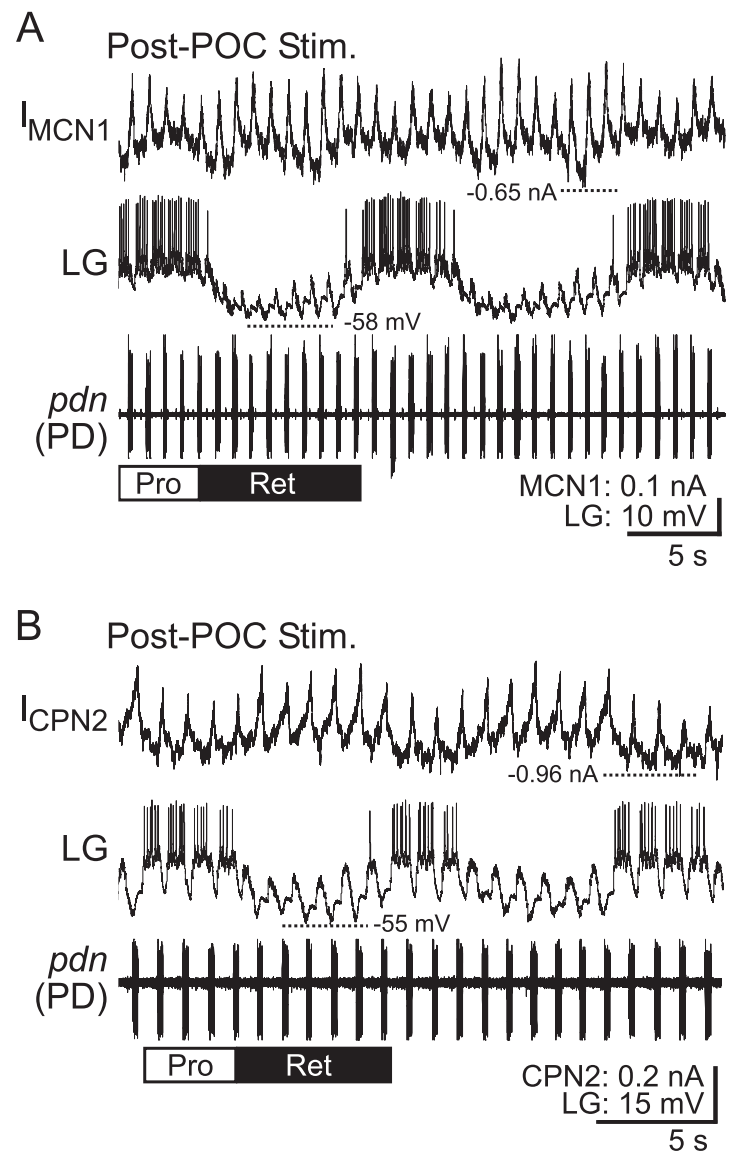

Figure 7. The $A B$ neuron-mediated IPSCS in MCN1 and CPN2 persist during the protraction phase of the $P O C$-triggered gastric mill rhythm. $A$, During the $P O C$-triggered gastric mill rhythm (evident in the pyloric-timed LG bursts), the AB-mediated IPSCs in MCN1 were present during both retraction (Ret) and protraction (Pro). The pyloric rhythm and the timing of $A B$ activity are represented by the PD (pdn) recording. The holding potential of MCN1 was $-65 \mathrm{mV}$. $\boldsymbol{B}$, The $A B$-mediated IPSCs in CPN2 were also present throughout both retraction (Ret) and protraction (Pro) during the POC-triggered gastric mill rhythm. The holding potential of CPN2 was $-65 \mathrm{mV}$. $\boldsymbol{A}$ and $\boldsymbol{B}$ are from separate preparations.

activity patterns that are time-locked to multiple rhythms. For instance, some neurons in the medullary lateral reticular nucleus exhibit activity patterns that are time-locked with both the respiratory and locomotor rhythms (Ezure and Tanaka, 1997). However, neither the pathways that mediate this coordinated activity nor the function of these activity patterns is identified in most systems.

Although the extent to which MCN1 and CPN2 are necessary and sufficient for driving the POC-gastric mill rhythm remains to be determined, they likely play significant roles in driving this version of the rhythm (Wood et al., 2004; Blitz et al., 2008). Previous work established that coactivation of MCN1 and CPN2 is necessary and sufficient for driving the VCN-gastric mill rhythm as well as the distinct gastric mill rhythm triggered by the gastropyloric receptor (GPR) neuron (Beenhakker and Nusbaum, 2004; Blitz et al., 2004). Unlike the distinct protraction phase activity patterns that occur during the VCN- and POCgastric mill rhythms, the VCN and GPR rhythms differ in cycle period and the activity levels of the associated motor neurons but share an overall tonic activity pattern during protraction and pyloric-timed activity during retraction. The distinction between these latter two rhythms appears to result from the additional ability of GPR to presynaptically inhibit the MCN1 axon termi- 

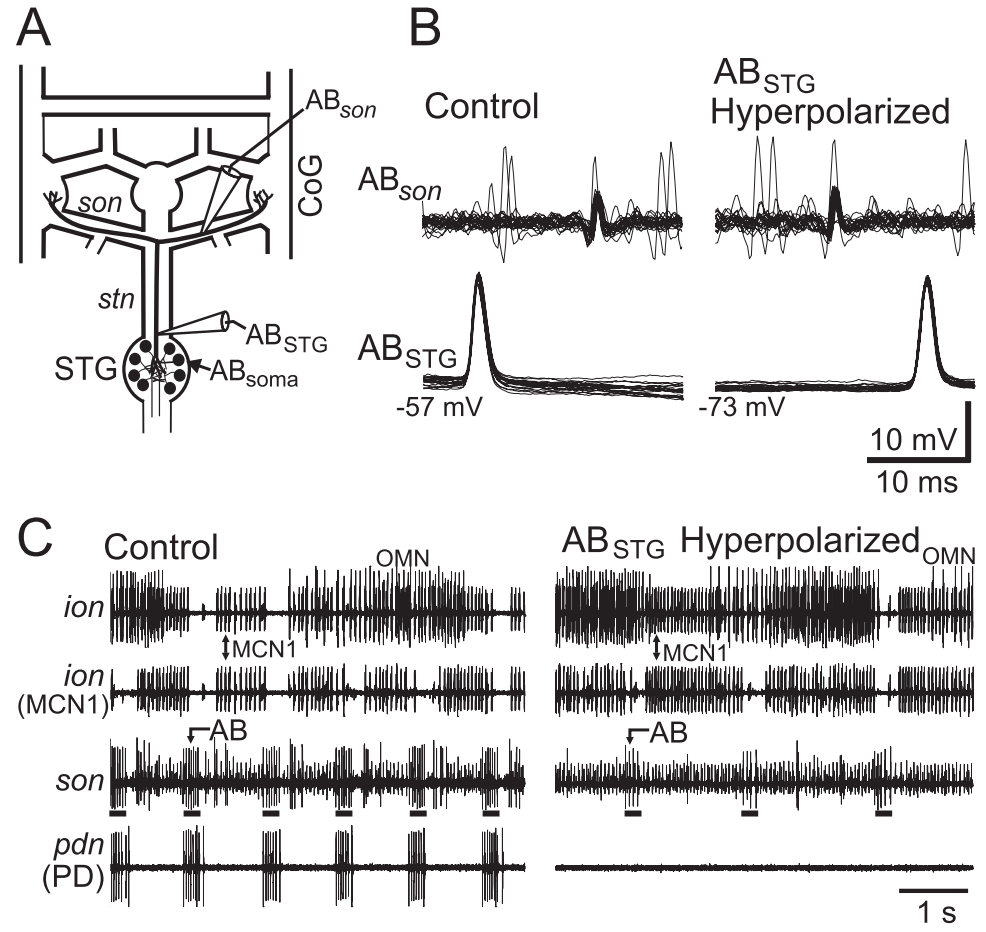

Figure 8. Hyperpolarizing the STG region of AB activates a secondary burst initiation zone in the CoGs. $A$, Schematic illustration of the $A B$ recording sites, including a sharp electrode intra-axonal recording near the STG (AB ${ }_{S T G}$ ) and a loose-patch recording of the $A B$ axon in the son nerve $\left(A B_{\text {son }}\right) \cdot B$, Multiple (20) overlaid traces were aligned to $A B$ action potentials recorded intra-axonally. Left, When the $A B_{S T G}$ was not regulated by current injection $\left(V_{m^{\prime}}-57 \mathrm{mV}\right)$, its action potentials were recorded first at $A B_{S T G}$ and then at $A B_{\text {son. }}$. Right, When $A B_{S T G}$ was hyperpolarized $(-73 \mathrm{mV})$, the $A B$ action potentials occurred first at $A B_{\text {son }}$ and then at $A B_{S T G}$, indicating that a secondary spike initiation zone was activated near or within a $C O G$. Both panels are from the same preparation. C, Left, Under control conditions, AB acted as the pacemaker for the pyloric rhythm (note the coactive AB and PD bursts) and each $A B$ burst (bars) inhibited $M C N 1$ activity. Right, When $A B_{S T G}$ was hyperpolarized, its secondary burst initiation zone was activated at a location anterior to the STG. This antidromic AB activity (bars) failed to effectively invade the STG, as evident from the lack of any associated PD neuron $(p d n)$ activity. Note that these antidromic bursts occurred with a longer cycle period than the orthodromic bursts. Despite not driving the pyloric rhythm in the STG, this secondary burst generating zone effectively inhibited MCN1 activity in the CoGs. The two ion recordings are the same, except that the OMN action potentials were digitally subtracted for the bottom ion recording to improve the clarity of the MCN1 activity (see Materials and Methods).

nals in the STG (Beenhakker et al., 2005). In several other motor systems, population coding is proposed to be the mechanism underlying the ability of single networks to generate multiple motor patterns (Georgopoulos, 1995; Kristan and Shaw, 1997; Lewis and Kristan, 1998; Liu and Fetcho, 1999). Recent work at the level of identified projection neurons in the Aplysia feeding system has provided additional support for the role of population coding (Morgan et al., 2002). This concept centers on the ability of distinct but related stimuli to activate separate, albeit overlapping populations of projection neurons. The ability of different extrinsic inputs to trigger distinct gastric mill rhythms despite their convergent coactivation of MCN1 and CPN2 supports the hypothesis that motor pattern selection can be mediated either by recruiting distinct projection neuron populations or differentially modifying the activity level and/or pattern of the same population.

It has also been suggested that CPG feedback may restrict the influence of higher-order and sensory inputs onto projection neurons to a particular phase of a rhythmic behavior (Deliagina et al., 2000; Pflieger and Dubuc, 2004). Therefore state-dependent regulation of CPG feedback such as we demonstrate here may provide flexibility in the influence of sensory signals during different motor patterns. Recent work has shown that there is both phase- and state-dependent filtering of sensory feedback to MCN1 and CPN2 during the VCN-gastric mill rhythm, albeit not obviously linked to the presynaptic inhibition of $\mathrm{AB}_{\mathrm{CoG}}$ (Beenhakker et al., 2005, 2007).

We have not yet determined the cellular and synaptic mechanisms by which the $\mathrm{AB}$ neuron is presynaptically inhibited within the CoG. Presumably, this presynaptic inhibition is mediated by one or more unidentified CoG neurons. It appears likely, however, that this CoG pathway has its activity regulated by the gastric mill CPG neuron interneuron 1 (Int1). Int 1 is the only gastric mill neuron that projects to and influences CoG neurons (Claiborne and Ayers, 1987; Norris et al., 1994). Further, Int1 and LG are reciprocally inhibitory and burst in alternation during the gastric mill rhythm (Coleman et al., 1995; Bartos et al., 1999). Therefore, Int 1 could provide the appropriate timing to the neuron(s) that inhibits $\mathrm{AB}_{\mathrm{CoG}}$ during VCN protraction by inhibiting that neuron during retraction. In fact, hyperpolarizing Int1 can elicit a VCN protraction-like response in $\mathrm{MCN1}$ and CPN2 even without previous VCN stimulation (Norris et al., 1994; B. J. Norris, M. J. Coleman, and M. P. Nusbaum, unpublished data). Thus, identifying targets of Int1 within the CoGs may enable identification of the neuron(s) that inhibit the $\mathrm{AB}_{\mathrm{CoG}}$ terminals. It is not clear why there is no comparable presynaptic inhibition of $\mathrm{AB}_{\mathrm{CoG}}$ during the POC-gastric mill rhythm, although the neuron(s) responsible for this focal action may be selectively inhibited by POC stimulation.

In conclusion, this study demonstrates that phasic presynaptic inhibition of CPG feedback helps shape projection neuron activity patterns. Furthermore, this local regulation is state dependent and consequently enables the same descending inputs to exhibit distinct activity patterns and drive different versions of a motor pattern under different conditions. Whether this statedependent regulation of feedback alters the impact of other incoming signals to projection neurons, such as phase-specific sensory inputs, remains to be determined.

\section{References}

Anderson WW, Barker DL (1981) Synaptic mechanisms that generate network oscillations in the absence of discrete postsynaptic potentials. J Exp Zool 216:187-191.

Arshavsky YI, Orlovsky GN, Perret C (1988) Activity of rubrospinal neurons during locomotion and scratching in the cat. Behav Brain Res 28:193-199.

Bartos M, Nusbaum MP (1997) Intercircuit control of motor pattern modulation by presynaptic inhibition. J Neurosci 17:2247-2256.

Bartos M, Manor Y, Nadim F, Marder E, Nusbaum MP (1999) Coordination of fast and slow rhythmic neuronal circuits. J Neurosci 19:6650-6660.

Beenhakker MP, Nusbaum MP (2004) Mechanosensory activation of a motor circuit by coactivation of two projection neurons. J Neurosci 24:6741-6750.

Beenhakker MP, Blitz DM, Nusbaum MP (2004) Long-lasting activation 


\section{A Pre-VCN Stim.}

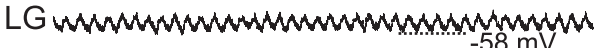

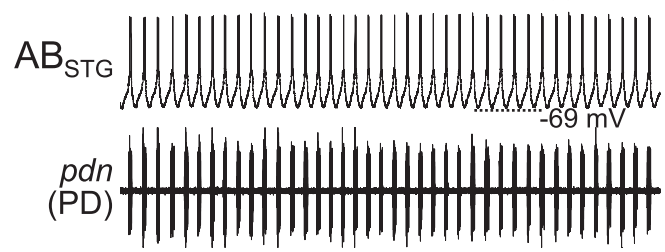

B Post-VCN Stim.
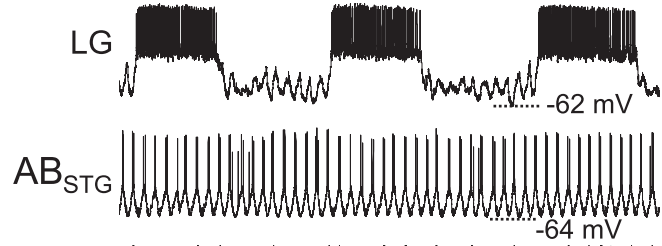

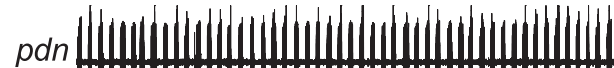

(PD)

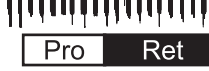

C

Post-VCN Stim. AB STG Hyperpolarized
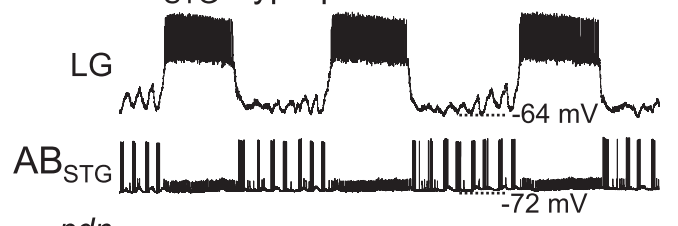

pdn

(PD)

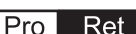

LG: $15 \mathrm{mV}$ AB: $20 \mathrm{mV}$

Figure 9. The secondary burst generating zone of the $A B$ neuron is suppressed during the protraction phase of the VCN-triggered gastric mill rhythm. $\boldsymbol{A}$, Before VCN stimulation, $\mathrm{B}_{\text {STG }}$ exhibited pyloric-timed membrane potential oscillations and fired action potentials at the peak of each oscillation. There was an ongoing pyloric rhythm (pdn) and no gastric mill rhythm (LG). $B$, During the VCN-triggered gastric mill rhythm, pyloric-timed bursts of $A_{S T G}$ action potentials persisted during both protraction (Pro) and retraction (Ret). $C$, When $\mathrm{AB}_{\text {STG }}$ was hyperpolarized, the pyloric rhythm ceased (note lack of $A B_{S T G}$ membrane potential oscillations and elimination of $P D$ activity) and the secondary $A B$ burst initiation zone was activated. These presumably CoG-initiated action potentials were eliminated during each protraction phase (Pro). The smaller amplitude events, most evident during each LG burst, are EPSPs from the projection neuron MCN5 (Norris et al., 1996). All panels are from the same preparation.

of rhythmic neuronal activity by a novel mechanosensory system in the crustacean stomatogastric nervous system. J Neurophysiol 91:78-91.

Beenhakker MP, DeLong ND, Saideman SR, Nadim F, Nusbaum MP (2005) Proprioceptor regulation of motor circuit activity by presynaptic inhibition of a modulatory projection neuron. J Neurosci 25:8794-8806.

Beenhakker MP, Kirby MS, Nusbaum MP (2007) Mechanosensory gating of proprioceptor input to modulatory projection neurons. J Neurosci 27:14308-14316.

Bellingham MC (1998) Driving respiration: the respiratory central pattern generator. Clin Exp Pharmacol Physiol 25:847-856.

Bernasconi P, Kohl J (1993) Analysis of co-ordination between breathing and exercise rhythms in man. J Physiol 471:693-706.

Blitz DM, Nusbaum MP (1999) Distinct functions for cotransmitters mediating motor pattern selection. J Neurosci 19:6774-6783.

Blitz DM, Christie AE, Coleman MJ, Norris BJ, Marder E, Nusbaum MP (1999) Different proctolin neurons elicit distinct motor patterns from a multifunctional neuronal network. J Neurosci 19:5449-5463.

Blitz DM, Beenhakker MP, Nusbaum MP (2004) Different sensory systems share projection neurons but elicit distinct motor patterns. J Neurosci 24:11381-11390.

Blitz DM, White RS, Saideman SR, Cook A, Christie AE, Nadim F, Nusbaum MP (2008) A newly identified extrinsic input triggers a distinct gastric mill rhythm via activation of modulatory projection neurons. J Exp Biol 211:1000-1011.

Bramble DM, Carrier DR (1983) Running and breathing in mammals. Science 219:251-256.

Buchanan JT, Einum JF (2008) The spinobulbar system in lamprey. Brain Res Rev 57:37-45.

Bucher D, Thirumalai V, Marder E (2003) Axonal dopamine receptors activate peripheral spike initiation in a stomatogastric motor neuron. J Neurosci 23:6866-6875.

Büschges A, Akay T, Gabriel JP, Schmidt J (2008) Organizing network action for locomotion: insights from studying insect walking. Brain Res Rev 57:162-171.

Calabrese RL (1980) Control of multiple impulse-initiation sites in a leech interneuron. J Neurophysiol 44:878-896.

Calabrese RL, Kennedy D (1974) Multiple sites of spike initiation in a single dendritic system. Brain Res 82:316-321.

Chevaleyre V, Takahashi KA, Castillo PE (2006) Endocannabinoidmediated synaptic plasticity in the CNS. Annu Rev Neurosci 29:37-76.

Claiborne BJ, Ayers J (1987) Functional anatomy and behavior. In: The crustacean stomatogastric system (Selverston AI, Moulins M, eds), pp 9-29. Berlin: Springer.

Clemens S, Massabuau JC, Legeay A, Meyrand P, Simmers J (1998) In vivo modulation of interacting central pattern generators in lobster stomatogastric ganglion: influence of feeding and partial pressure of oxygen. J Neurosci 18:2788-2799.

Coleman MJ, Nusbaum MP (1994) Functional consequences of compartmentalization of synaptic input. J Neurosci 14:6544-6552.

Coleman MJ, Nusbaum MP, Cournil I, Claiborne BJ (1992) Distribution of modulatory inputs to the stomatogastric ganglion of the crab, Cancer borealis. J Comp Neurol 325:581-594.

Coleman MJ, Meyrand P, Nusbaum MP (1995) A switch between two modes of synaptic transmission mediated by presynaptic inhibition. Nature 378:502-505.

Deliagina TG, Zelenin PV, Fagerstedt P, Grillner S, Orlovsky GN (2000) Activity of reticulospinal neurons during locomotion in the freely behaving lamprey. J Neurophysiol 83:853-863.

Dubuc R, Grillner S (1989) The role of spinal cord inputs in modulating the activity of reticulospinal neurons during fictive locomotion in the lamprey. Brain Res 483:196-200.

Dubuc R, Brocard F, Antri M, Fénelon K, Gariépy JF, Smetana R, Ménard A, Le Ray D, Viana Di Prisco G, Pearlstein E, Sirota MG, Derjean D, St-Pierre M, Zielinski B, Auclair F, Veilleux D (2008) Initiation of locomotion in lampreys. Brain Res Rev 57:172-182.

Eisen JS, Marder E (1982) Mechanisms underlying pattern generation in lobster stomatogastric ganglion as determined by selective inactivation of identified neurons. III. Synaptic connections of electrically coupled pyloric neurons. J Neurophysiol 48:1392-1415.

El Manira A, Kyriakatos A, Nanou E, Mahmood R (2008) Endocannabinoid signaling in the spinal locomotor circuitry. Brain Res Rev 57:29-36.

Ezure K, Tanaka I (1997) Convergence of central respiratory and locomotor rhythms onto single neurons of the lateral reticular nucleus. Exp Brain Res 113:230-242.

Frost WN, Katz PS (1996) Single neuron control over a complex motor program. Proc Natl Acad Sci U S A 93:422-426.

Gao P, Bermejo R, Zeigler HP (2001) Whisker deafferentation and rodent whisking patterns: behavioral evidence for a central pattern generator. J Neurosci 21:5374-5380.

Georgopoulos AP (1995) Current issues in directional motor control. Trends Neurosci 18:506-510.

Gillette R, Kovac MP, Davis WJ (1978) Command neurons in Pleurobranchaea receive synaptic feedback from the motor network they excite. Science 199:798-801.

Goldberg D, Nusbaum MP, Marder E (1988) Substance P-like immunoreactivity in the stomatogastric nervous systems of the crab Cancer borealis and the lobsters Panulirus interruptus and Homarus americanus. Cell Tissue Res 252:515-522. 


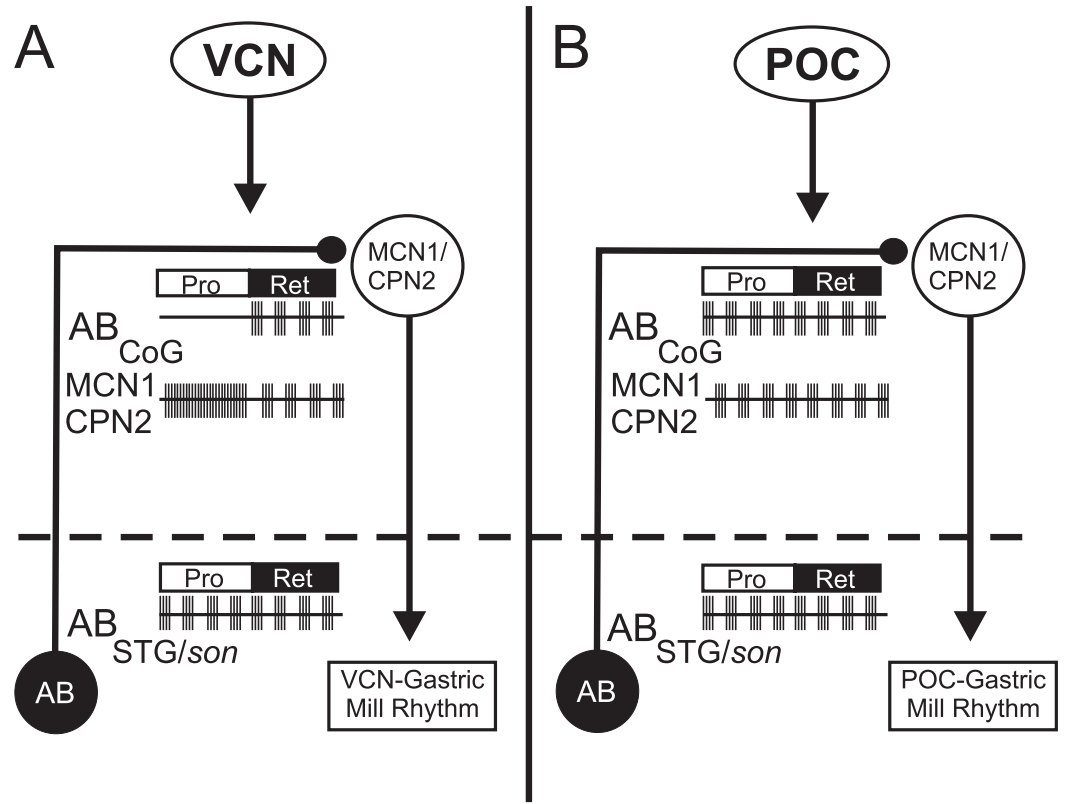

Figure 10. State-dependent presynaptic inhibition of $A B$ feedback onto $M C N 1$ and $C P N 2$ underlies the distinct POC-and VCN-triggered gastric mill protractor phase activity patterns. $A$, During the VCN-gastric mill rhythm, the $\mathrm{C} 0 \mathrm{G}$ axon terminals of the $A B$ neuron are presynaptically inhibited during the protractor phase (Pro). This eliminates $A B$ inhibitory feedback onto MCN1 and CPN2 in the $C O G$, whereas AB activity persists in the STG. This presynaptic inhibition switches the projection neurons from a pyloric rhythm-timed activity pattern during retraction (Ret) to a tonic firing pattern during protraction. This tonic firing pattern in turn drives tonic firing of the gastric mill protractor neuron $L G$ in the STG. $B$, During the POC-gastric mill rhythm, there is no presynaptic inhibition of AB in the CoGs. Therefore, MCN1 and CPN2 activity is pyloric-timed during both protraction (Pro) as well as retraction (Ret), which in turn drives the protractor $L G$ neuron to fire in a pyloric rhythm-timed pattern.

Graubard K, Raper JA, Hartline DK (1980) Graded synaptic transmission between spiking neurons. Proc Natl Acad Sci U S A 77:3733-3735.

Graubard K, Raper JA, Hartline DK (1983) Graded synaptic transmission between identified spiking neurons. J Neurophysiol 50:508-521.

Grillner S, Wallén P, Saitoh K, Kozlov A, Robertson B (2008) Neural bases of goal-directed locomotion in vertebrates-an overview. Brain Res Rev $57: 2-12$.

Heinzel HG, Weimann JM, Marder E (1993) The behavioral repertoire of the gastric mill in the crab, Cancer pagurus: an in situ endoscopic and electrophysiological examination. J Neurosci 13:1793-1803.

Jordan LM, Liu J, Hedlund PB, Akay T, Pearson KG (2008) Descending command systems for the initiation of locomotion in mammals. Brain Res Rev 57:183-191.

Kawahara K, Kumagai S, Nakazono Y, Miyamoto Y (1989) Coupling between respiratory and stepping rhythms during locomotion in decerebrate cats. J Appl Physiol 67:110-115.

Kiehn O (2006) Locomotor circuits in the mammalian spinal cord. Annu Rev Neurosci 29:279-306.

Kristan WB Jr, Shaw BK (1997) Population coding and behavioral choice. Curr Opin Neurobiol 7:826-831.

Kristan WB Jr, Calabrese RL, Friesen WO (2005) Neuronal control of leech behavior. Prog Neurobiol 76:279-327.

Lewis JE, Kristan WB Jr (1998) A neuronal network for computing population vectors in the leech. Nature 391:76-79.

Liu KS, Fetcho JR (1999) Laser ablations reveal functional relationships of segmental hindbrain neurons in zebrafish. Neuron 23:325-335.

Lomelí J, Quevedo J, Linares P, Rudomin P (1998) Local control of information flow in segmental and ascending collaterals of single afferents. Nature 395:600-604.

Marder E, Bucher D (2001) Central pattern generators and the control of rhythmic movements. Curr Biol 11:R986-R996.

Marder E, Bucher D (2007) Understanding circuit dynamics using the stomatogastric nervous system of lobsters and crabs. Annu Rev Physiol 69:291-316.

Messinger DI, Kutz KK, Le T, Verley DR, Hsu YW, Ngo CT, Cain SD, Birmingham JT, Li L, Christie AE (2005) Identification and charac- terization of a tachykinin-containing neuroendocrine organ in the commissural ganglion of the crab Cancer productus. J Exp Biol 208:3303-3319.

Meyrand P, Weimann JM, Marder E (1992) Multiple axonal spike initiation zones in a motor neuron: serotonin activation. J Neurosci 12:2803-2812.

Miller JP, Selverston AI (1982a) Mechanisms underlying pattern generation in lobster stomatogastric ganglion as determined by selective inactivation of identified neurons. II. Oscillatory properties of pyloric neurons. J Neurophysiol 48:1378-1391.

Miller JP, Selverston AI (1982b) Mechanisms underlying pattern generation in lobster stomatogastric ganglion as determined by selective inactivation of identified neurons. IV. Network properties of pyloric system. J Neurophysiol 48:1416-1432.

Morgan PT, Jing J, Vilim FS, Weiss KR (2002) Interneuronal and peptidergic control of motor pattern switching in Aplysia. J Neurophysiol 87:49-61.

Morin D, Viala D (2002) Coordinations of locomotor and respiratory rhythms in vitro are critically dependent on hindlimb sensory inputs. J Neurosci 22:4756-4765.

Moulins M, Vedel JP, Nagy F (1979) Complex motor neurone in crustacea: three axonal spike initiating zones in three different ganglia. Neurosci Lett 13:231-236.

Nagy F, Cardi P, Cournil I (1994) A rhythmic modulatory gating system in the stomatogastric nervous system of Homarus gammarus. I. Pyloric-related neurons in the commissural ganglia. J Neurophysiol 71:2477-2489.

Norris BJ, Coleman MJ, Nusbaum MP (1994) Recruitment of a projection neuron determines gastric mill motor pattern selection in the stomatogastric nervous system of the crab, Cancer borealis. J Neurophysiol 72:1451-1463.

Norris BJ, Coleman MJ, Nusbaum MP (1996) Pyloric motor pattern modification by a newly identified projection neuron in the crab stomatogastric nervous system. J Neurophysiol 75:97-108.

Nusbaum MP (1986) Synaptic basis of swim initiation in the leech. III. Synaptic effects of serotonin-containing interneurones (cells 21 and 61) on swim CPG neurones (cells 18 and 208). J Exp Biol 122:303-321.

Nusbaum MP, Marder E (1989) A modulatory proctolin-containing neuron (MPN). II. State-dependent modulation of rhythmic motor activity. J Neurosci 9:1600-1607.

Nusbaum MP, Blitz DM, Swensen AM, Wood D, Marder E (2001) The roles of co-transmission in neural network modulation. Trends Neurosci 24:146-154.

Pelkey KA, McBain CJ (2007) Differential regulation at functionally divergent release sites along a common axon. Curr Opin Neurobiol 17:366-373.

Perrins R, Weiss KR (1998) Compartmentalization of information processing in an Aplysia feeding circuit interneuron through membrane properties and synaptic interactions. J Neurosci 18:3977-3989.

Pflieger JF, Dubuc R (2004) Vestibulo-reticular projections in adult lamprey: their role in locomotion. Neuroscience 129:817-829.

Pinheiro PS, Mulle C (2008) Presynaptic glutamate receptors: physiological functions and mechanisms of action. Nat Rev Neurosci 9:423-436.

Raper JA (1979) Nonimpulse-mediated synaptic transmission during the generation of a cyclic motor program. Science 205:304-306.

Rosen SC, Teyke T, Miller MW, Weiss KR, Kupfermann I (1991) Identification and characterization of cerebral-to-buccal interneurons implicated in the control of motor programs associated with feeding in Aplysia. J Neurosci 11:3630-3655.

Rossignol S, Dubuc R, Gossard JP (2006) Dynamic sensorimotor interactions in locomotion. Physiol Rev 86:89-154. 
Saideman SR, Blitz DM, Nusbaum MP (2007) Convergent motor patterns from divergent circuits. J Neurosci 27:6664-6674.

Sasaki K, Due MR, Jing J, Weiss KR (2007) Feeding CPG in Aplysia directly controls two distinct outputs of a compartmentalized interneuron that functions as a CPG element. J Neurophysiol 98:3796-3801.

Saunders SW, Rath D, Hodges PW (2004) Postural and respiratory activation of the trunk muscles changes with mode and speed of locomotion. Gait Posture 20:280-290.

Syed NI, Winlow W (1991) Coordination of locomotor and cardiorespiratory networks of Lymnaea stagnalis by a pair of identified interneurones. J Exp Biol 158:37-62.

Weimann JM, Meyrand P, Marder E (1991) Neurons that form multiple pattern generators: identification and multiple activity patterns of gastric/ pyloric neurons in the crab stomatogastric system. J Neurophysiol 65:111-122.

Westberg KG, Kolta A, Clavelou P, Sandström G, Lund JP (2000) Evidence for functional compartmentalization of trigeminal muscle spindle afferents during fictive mastication in the rabbit. Eur J Neurosci 12:1145-1154.

Wood DE, Manor Y, Nadim F, Nusbaum MP (2004) Intercircuit control via rhythmic regulation of projection neuron activity. J Neurosci 24:7455-7463.

Zecević D (1996) Multiple spike-initiation zones in single neurons revealed by voltage-sensitive dyes. Nature 381:322-325. 